\title{
Composição estético-formal de familia de produtos: modelo generativo usando analogia biológica
}

\author{
Aesthetic-formal composition of product families: generative model \\ using biological analogy
}

\author{
SULZBACHER, Tânia \\ Universidade Federal do Rio Grande do Sul - UFRGS I tania.sulzbacher@gmail.br \\ TEIXEIRA, Fábio \\ Universidade Federal do Rio Grande do Sul - UFRGS I fabiogt@ufrgs.br
}

\begin{abstract}
Resumo
Em projetos de desenvolvimento de família de produtos, além do equacionamento de fatores que melhor atendam os requisitos funcionais individuais de cada membro, também se faz necessária a manutenção da coerência estilística para que a mesma seja percebida como um conjunto, ou seja, que preserve uma unidade formal reconhecível pelo usuário, denominada como similaridade morfológica. Diante disto, o presente trabalho apresenta uma abordagem de geração de alternativas baseada no princípio da hereditariedade da genética natural, onde sucessivas gerações mantêm semelhanças de fenótipo em razão da contínua transferência de instruções em forma de código, o genótipo. Para tanto, o modelo generativo aqui proposto vincula os padrões da construção geométrica da morfologia dos elementos da família de produtos aos elementos e estruturas da genética, permitindo que os mesmos sejam tratados como unidades cromossômicas passíveis de manipulação por algoritmos genéticos e sujeitos aos princípios das combinações e mutações análogas ao contexto biológico.
\end{abstract}

Palavras Chave: Processo de Design. Geração de alternativas. Família de produtos.

\section{Abstract}

The development of product families requires, on the one hand, the management of assets to meet functional requirements in each product and, on the other hand, the maintenance of the stylistic coherence so that the family is perceived as a whole. That is, the aesthetic unity is recognizable by the user, which is called morphological similarity. This work presents an alternative generation approach based on the principle of heredity of natural genetics, in which successive generations maintain phenotype similarities due to the continuous transfer of information through genetic code - the genotype. In order to do so, the generative model we propose links the patterns of the geometric construction in the morphology of elements within the product family to the elements and structures of Genetics. Thus, they behave as chromosomal units, that is, they can be maneuvered by genetic algorithms and subjected to combination/ mutation principles of the biological context.

Keywords: Design Process. Concept Generation. Product Families. 


\section{INTRODUC̣ÃO}

Em processo de projeto, a etapa de "Geração de Alternativas", denominada etapa "lluminação" no processo criativo, é o momento de gerar e desenvolver; e posteriormente, avaliar e selecionar as soluções geradas em uma etapa chamada "Verificação", que é definida por Löbach (2001), como fase em que ficam visíveis todas as ideias materializando-se através de desenhos e modelos preliminares que poderão ser comparados, possibilitandose encontrar a solução mais próxima do atendimento dos critérios elaborados previamente. Para orientar a geração de alternativas, são usadas ferramentas e técnicas que podem ser classificadas em dois grupos: intuitivos e sistemáticos. Os métodos definidos como sistemáticos, como por exemplo, a Matriz Morfológica, consiste em uma sequência lógica de ações que resultam em soluções alternativas para um determinado problema (BACK, et al. 2008). Ou seja, para cada parte do problema podemos ter mais de um princípio de solução o que gera por vezes inúmeras combinações possíveis e uma ampla massa de dados. Neste caso, os algoritmos genéticos (AGs) que simulam a evolução e a seleção natural dos seres vivos tem se mostrado como alternativa de apoio, pois permitem a construção de modelos computacionais capazes de auxiliar na tarefa de gerar e avaliar múltiplas soluções (TEIXEIRA, 2016). Para tanto, no caso de desenvolvimento de família de produtos, onde variantes estéticoformais são procuradas, há, inicialmente, a necessidade de desenvolver uma estrutura de dados que permita a equivalência dos elementos e operadores da linguagem geométrica de uma composição formal para a linguagem genética e posteriormente para a linguagem computacional, possibilitando-se assim a manipulação das unidades pelos AGs.

O mecanismo descrito neste trabalho se delimita à famílias de produtos constituídas a partir de formas cilíndricas isométricas geradas por revolução; e que usam a geometria do aspecto estético-formal como referencial semântico de unidade para composição da percepção de família. Tais composições são encontradas em objetos do cotidiano como: louças, taças, garrafas; em embalagens de consumo como: laticínios, geleias e condimentos, produtos de higiene e limpeza; e aplicadas a bens de consumo como: eletrônicos, lâmpadas, etc. Eventualmente, o corpo do objeto gerado por revolução possui componentes acessórios de acordo com seus requisitos funcionais, como: pegas, vertedores, tampas, entre outros. A Figura 1 apresenta o exemplo de membros de uma família de produtos e suas respectivas sequências de arcos tangentes que definem as geratrizes das superfícies e determinam a sua unidade formal. 

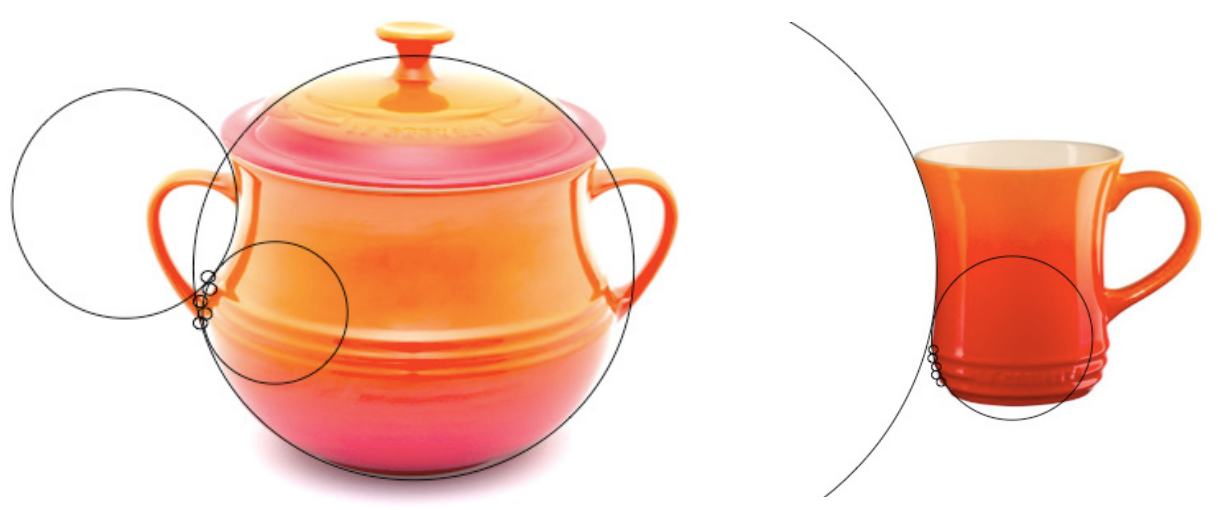

Fonte: lecruset.com (2018).

Para gerir a coerência formal entre os membros de uma família de produtos, este trabalho propõe a elaboração de um mecanismo baseado em um princípio natural que permite a derivação de uma forma seminal para os demais membros do conjunto, com a finalidade de relacionar as regras de composição de formas com características estético-formais similares através dos princípios naturais de hereditariedade e evolução. Nachtigall (2010), diz que a transposição das operações e dos fenômenos naturais para as áreas de Engenharia, Arquitetura e Design, podem ocorrer através da abordagem denominada Analogia Biológica, cujas as etapas se dividem em: Investigação, Abstração e Implementação, sendo a identificação dos princípios de um determinado fenômeno natural; a transcrição destes princípios e sua aplicação em contexto de projeto, respectivamente.

\section{GESTÃO DA COERÊNCIA FORMAL ATRAVÉS DOS CONCEITOS DE HEREDITARIEDADE}

Incialmente foi investigado o fenômeno natural denominado hereditariedade, que representa a condição de semelhança existente entre ascendentes e descendentes, através de uma contínua transferência de instruções em forma de código denominada de genótipo, que estão inscritas no material genético e orientam a formação e o desenvolvimento dos seres vivos, se manifestando através de suas características externas, morfológicas e fisiológicas chamadas de fenótipo (BURNS, 1986). No contexto natural, a hereditariedade ocorre através dos genes, sendo estes uma macromolécula de dupla hélice, semelhante a uma espiral, chamada ácido desoxirribonucleico, abreviado para DNA. O DNA corresponde assim, ao material hereditário que passa de uma geração à seguinte, ditando as propriedades inerentes de uma 
espécie (Figura 2). Cada célula em um organismo contém, tipicamente, um ou dois grupos do complemento básico do DNA, chamado de genoma (GRIFFITHS et al., 2001).

Figura 2 - Estruturas codificadas do genótipo - DNA.

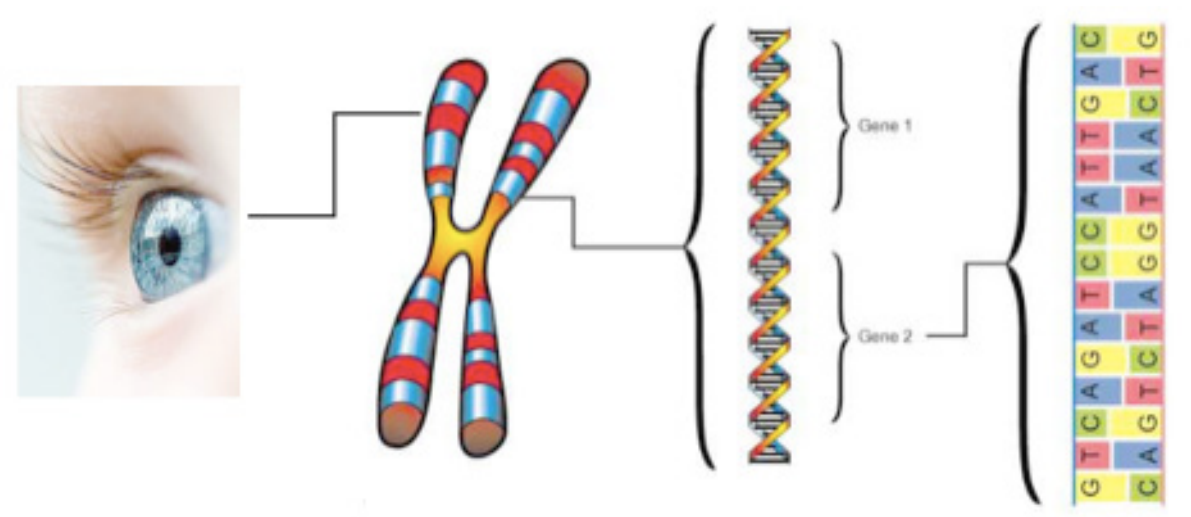

Fonte: $\mathrm{O}$ autor.

Para aproximar o mecanismo da hereditariedade natural ao método generativo proposto por este trabalho, houve a necessidade de simplificar e correlacionar os agentes de ambos os contextos para promover a sua viabilidade técnica. Enquanto no contexto natural a codificação está sob a forma de uma sequência de subunidades químicas, no contexto dos métodos generativos temos a gramática da forma como meio de composição de características estético-formais. O projeto generativo é resultado de um algoritmo composto por regras semânticas, referentes ao significado e à interpretação dos elementos projetuais; e sintáticas, que se referem às relações formais de estruturação tais como: ordem, arranjo e subordinação (MITCHELL, 1992).

A partir deste raciocínio George Stiny e James Gips desenvolveram a Gramática da Forma, que consiste em um sistema de geração de formas baseado em regras e tem sua origem na gramática generativa do linguista Noam Chomsky (CELANI et al., 2006). A gramática é definida como a teoria de estruturação de uma linguagem que determina um conjunto de regras que irão ordenar a combinação de palavras de modo a produzir sentenças gramaticais válidas (GONCALVES, 2007). Neste sentido, a gramática das formas é aplicada com o objetivo de estruturar a maneira de combinar as formas manipuladas de acordo com as regras, podendo produzir uma classe de modelos em um estilo particular para gerar diversas formas emergentes seguindo uma mesma linguagem de design (CHA; GERO, 2006). Sendo assim, é possível compreender que um conjunto de regras formais compostas de operações determinadas por entes geométricos, variáveis de dimensão, relações topológicas, relações de inter-relações e de transformações isométricas, além das operações lógicomatemáticas, podem corresponder a codificação denominada no contexto natural em Genótipo e sua formalização espacial em Fenótipo (Figura 3). 
Figura 3 - Conceito de Genótipo e Fenótipo.
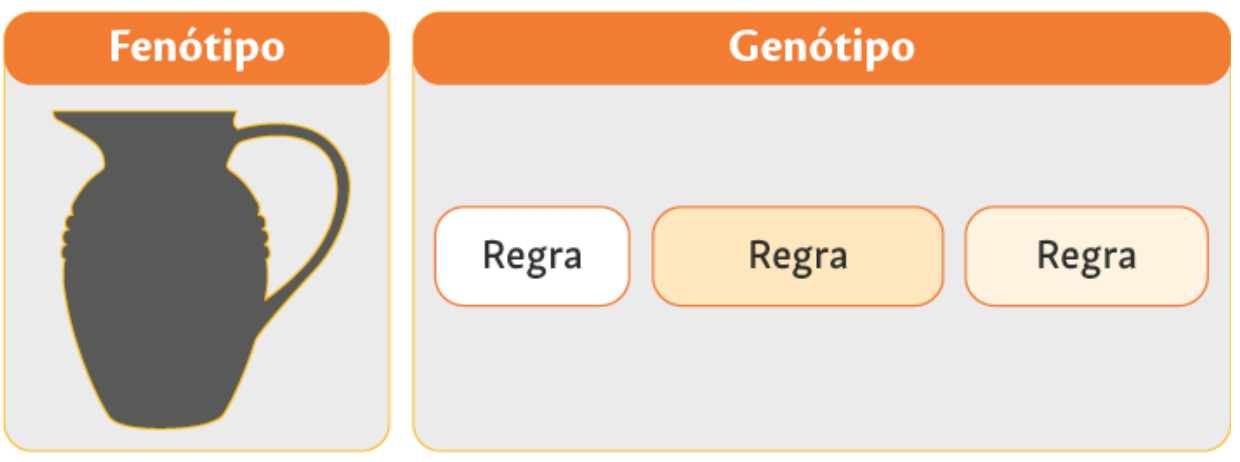

Fonte: $\mathrm{O}$ autor.

Ao se estabelecer uma categoria conceitual como objeto de investigação formal, se percebem as variações formais do desenho da superfície (permitidas pela manipulação da geratriz, ou seja, variações de raio em relação ao eixo ao longo da altura do artefato) como agente unificador do conjunto (família). Lembrando que um produto pode ser identificado pelas suas proporções, linhas orgânicas ou linhas inclinadas características, se adotou a construção da geratriz por meio de arcos euclidianos para determinar e controlar a sua composição e decomposição formal.

A Figura 4 exemplifica o raciocínio de construção de uma geratriz através de arcos de circunferência dispondo 3 (três) circunferências com inter-relações de contato, cujos arcos adjacentes intercalados evidenciam uma geratriz. As circunferências que originaram os arcos, possuem relação topológica e de transformação, e dimensionamentos.

Figura 4 - Esquema llustrado da Composição da Forma usando Superfícies de Revolução

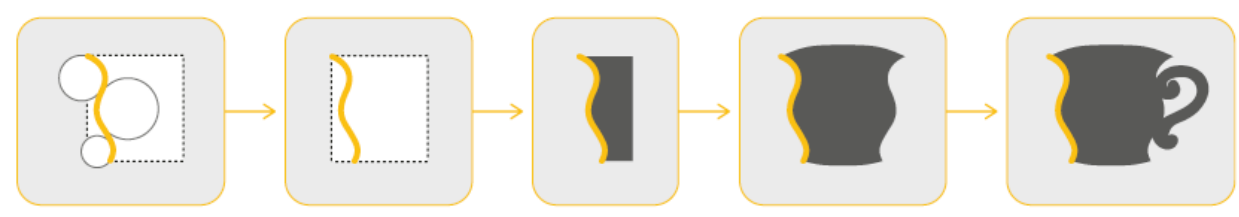

Fonte: $\mathrm{O}$ autor.

Uma vez isolada a geratriz de uma superfície e compreendida quais são seus entes geométricos, seus operadores e relações topológicas e de transformação através do uso da gramática da forma, se torna viável a obtenção da fórmula geométrica para construção de uma nova forma a partir desta mesma sequência de geração, apenas alterando o conteúdo de suas variáveis. 


\section{TRANSCRIC̣ÃO DO VOCABULÁRIO GEOMÉTRICO PARA O GENÉTICO}

Stiny (1980 ) divide a estruturação da gramática da forma em cinco etapas, definidas como: Vocabulário: formas primitivas e de suas potenciais possibilidades de composição (Fig. 5.1); Relações Espaciais: combinação do vocabulário a partir de operações booleanas, categorias de inter-relação e transformações isométricas e paramétricas (Fig. 5.2); Regras Formais: A partir das relações espaciais, são definidas regras de transformação do tipo $A$-> B (ao encontrar A, substitua por B) (Fig. 5.3); se permitindo assim a composição de formas emergentes (STINY, 1980).

Figura 5 - Etapas de Estruturação da Gramática da Forma.
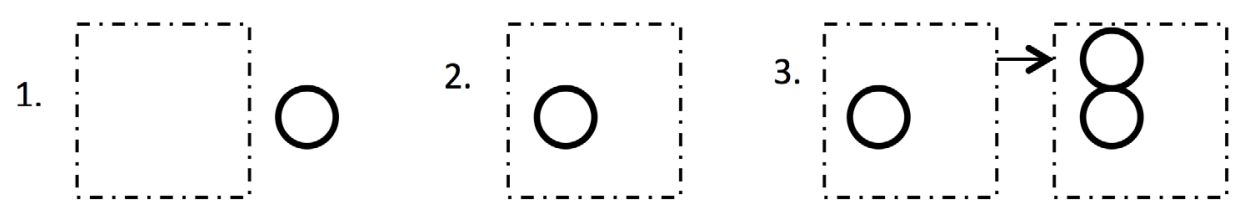

Fonte: $\mathrm{O}$ autor.

O Quadro 1 demonstra o exemplo da composição de uma geratriz utilizando a sequência de passos e os elementos da gramática da forma para identificação e compreensão da sua sequência generativa. Com isso é possível evidenciar o número de elementos, de regras e o tipo de operações que compõem a forma.

Sendo assim, retomando a analogia com a genética, foi possível estabelecer que uma regra formal corresponde ao conceito de gene, e o conjunto de regras formais necessárias para a composição de uma geratriz, ou seja, o conjunto de genes, corresponde a um cromossomo (Figura 6). Portanto, cada geratriz terá o seu cromossomo composto por uma sequência de genes que possuem material genético que coletivamente compõe o genótipo, onde as codificações manifestam no fenótipo. O número de regras formais pode variar de acordo com a complexidade geométrica do objeto, sendo que o número de regras não se vincula a uma espécie. Conforme visto anteriormente, uma categoria conceitual pode ser composta por membros de diferentes espécies, exemplificado, podemos considerar dois elementos da mesma espécie (duas xícaras) com um número diferente de regras. Assim como podemos ter dois elementos de espécies diferentes (xícara e bule) com o mesmo número de regras. 
Quadro 1 - Composição de Geratriz utilizando Gramática da Forma.

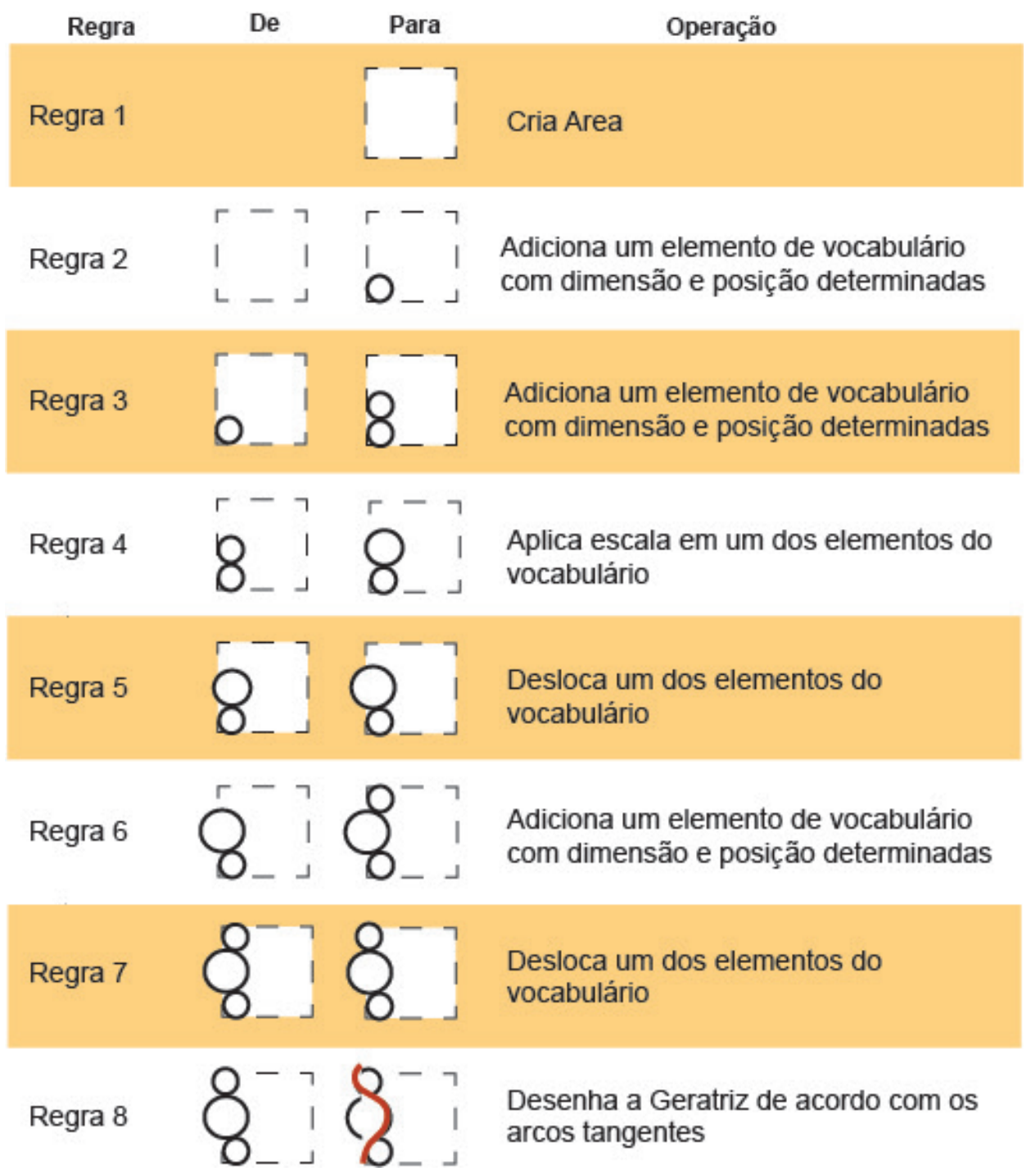

Fonte: $\mathrm{O}$ autor.

Figura 6 - Cromossomo composto por Regras Formais (Genes).

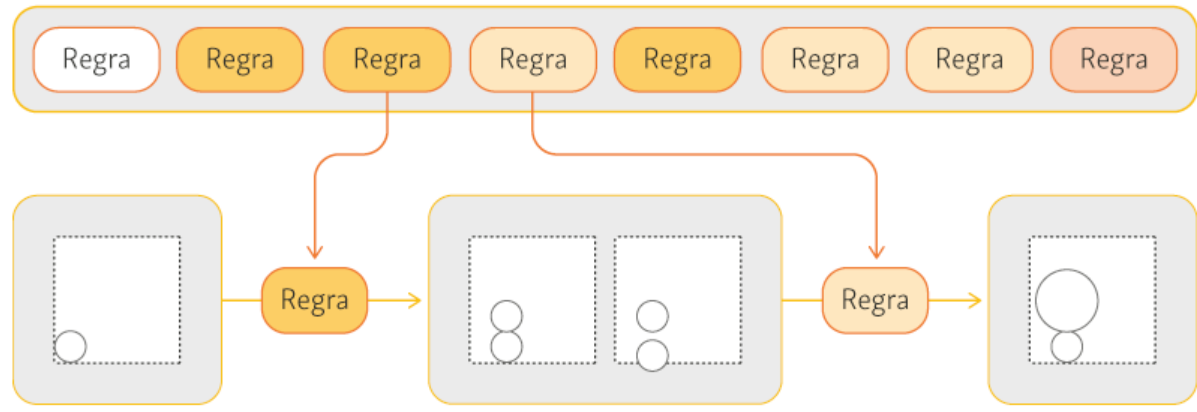

Fonte: $\mathrm{O}$ autor. 
A composição de uma forma pode ser descrita através de seus elementos componentes e conjunto de operações se obtendo assim uma regra (ou um conjunto de regras, dependendo da complexidade) para criação desta forma. Se pode então corresponder este conjunto de regras ao conceito de genótipo, e a forma composta ao conceito de fenótipo. A partir disto foi construído um conjunto de regras generativas para compor um exemplo para análise conforme visto no Quadro1. Para a sua composição, foram necessárias o uso de dois distintos elementos de vocabulário, o primeiro que determina o espaço dimensional do objeto, definindo o raio $(r)$ e altura $(h)$ limites do objeto final; e uma circunferência para permitir a construção dos arcos. Foram também necessárias oito regras formais que realizaram Adição, Escala e Deslocamento, que correspondem à operações booleanas e à relações de topológicas e de transformação.

\section{TRANSCRIC̣ÃO DO VOCABULÁRIO GENÉTICO PARA O COMPUTACIONAL}

Para a implementação do mecanismo em um modelo computacional, o vocabulário genético precisa ser adaptado ao vocabulário computacional, de maneira que possa ser manipulado por um algoritmo. Um algoritmo é uma sequencia finita e bem definida de passos que, quando executados, realizam uma tarefa especifica ou resolvem um problema. Portanto são propriedades de um algoritmo ações simples e bem definidas (não pode haver ambiguidade, ou seja, cada instrução representa uma ação que deve ser entendida e realizada); há uma sequencia ordenada de ações; e há um conjunto finito de passos. Sua estrutura é composta por declaração de constantes e variáveis; comandos de atribuição; estruturas de seleção e estruturas de repetição e chamada de funções ou procedimentos. (DAVIS, 1990).

O resultado obtido com a estruturação da geratriz usando a gramática da forma, permitiu a observação de que o número de arcos (Figura. 7.1), corresponde ao número de elementos de vocabulário inicial (Figura 7.2). Portanto obteve-se o primeiro identificador de variável denominado "nev" (nev = número de elementos de vocabulário). Para fins de identificação da proporção entre os círculos adota-se que a medida do diâmetro " $\mathrm{d}$ " inicial dos círculos (elementos de vocabulário) será o mesmo para todos e ocupando a altura " $\mathrm{h}$ " do corpo do objeto, sendo assim: 
Figura 7 - Numero de Elementos de Vocabulário.
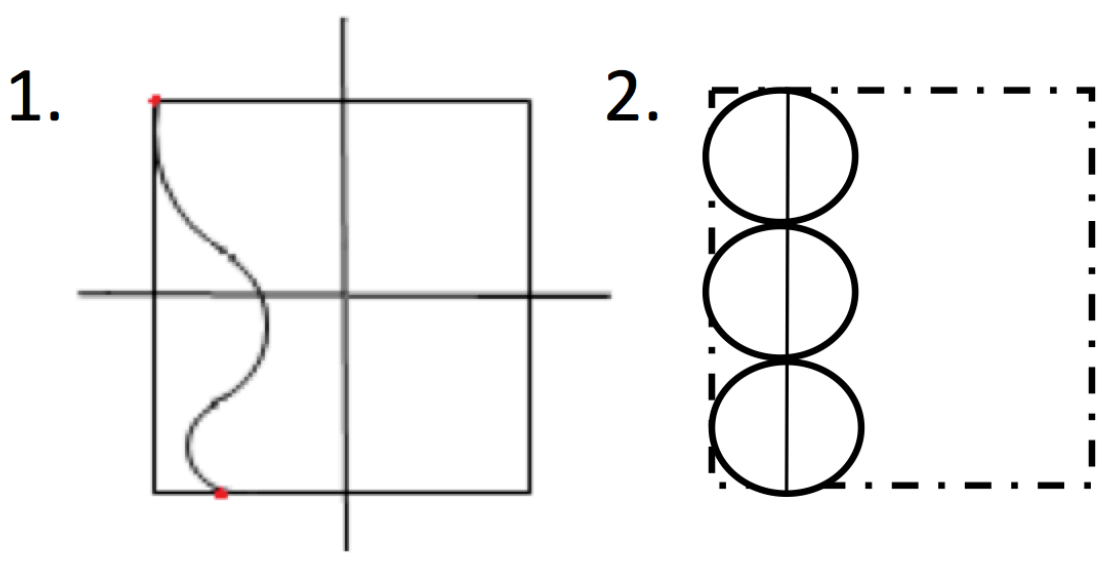

Fonte: o autor.

Uma vez evidenciada a organização e a relação entre os elementos da gramática, foi também possível observar a repetição de algumas operações, permitindo-se assim isolar e estabelecer regras distintas que podem operar com diferentes variáveis. Neste caso as etapas foram agrupadas em 4 (quatro) diferentes regras:

Regra 0: O Quadro 2 apresenta a regra em é estabelecido o "Nev" número inicial de elementos de vocabulário. A altura $(h)$ corresponde à altura do objeto e define a altura da composição (empilhamento) de elementos do vocabulário inicial; e a largura (s) corresponde a largura do elemento. A regra é compreendida pela seguinte função: CriarArea(h,s,nev).

Quadro2 - Regra 0.

$\begin{array}{llll}\text { Regra } & \text { De } & \text { Para } & \text { Operação } \\ \text { Regra } 1 & \text { Cria Area }\end{array}$

Fonte: o autor.

Regra 1: O Quadro 3 apresenta a sequência de geração que evidencia que a regra que adiciona elementos à composição pode estabelecer a parametrização dos seguintes parâmetros: forma, escala e translação. A regra é representada pela seguinte notação: Adicionar (forma; escala; translação; inter-relação; percprof). O parâmetro "inter-relação" determina o tipo de inter-relação (Superposição ou União) entre a forma anterior e a atual. Já o parâmetro "percprof" (percentual de profundidade) determina o percentual de profundidade da superposição ou união, sendo que o valor "O" (zero) indica contato entre as duas formas e o valor "100"(cem) indica sobreposição total. 
Quadro 3 - Regra 1.

\begin{tabular}{llll} 
Regra & De & \multicolumn{1}{c}{ Operação } \\
Regra 1 & & $\begin{array}{l}\text { Adiciona um elemento de vocabulário } \\
\text { com dimensão e posição determinadas } \\
\text { Adição de Circulo }\end{array}$ \\
Regra 2 & & &
\end{tabular}

Fonte: o autor.

Regra 2: Nesta regra é definido movimento da geratriz em que a o elemento do vocabulário também é adicionado, pode sofrer operação relacionado à escala e translação, porém determinando sentido oposto ao movimento da geratriz provocado pela função "Adicionar" (Quadro 4). Os movimentos com esta característica são representados pela seguinte notação: Subtrair (forma; escala; translação; inter-relação; percprof).

Quadro 4 - Regra 2.

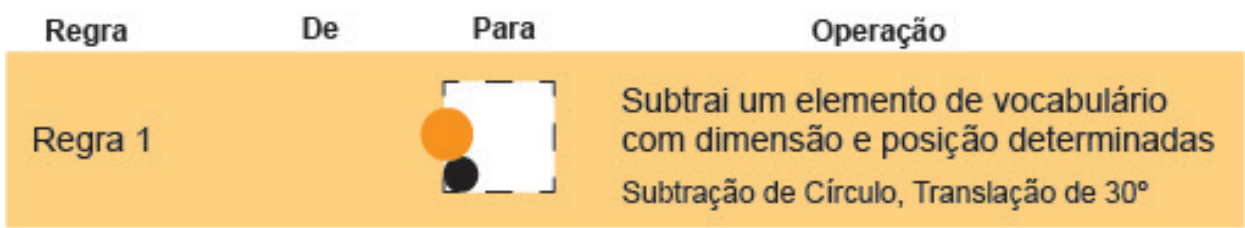

Fonte: o autor.

Em caso de repetição de regras a função Repetir (Regra 3) é usada associada às funções Adicionar e Subtrair com os seguintes parâmetros: Reg (regra que será repetida), n (número de repetições) e traj (trajetória a ser realizada). A operação é representada pela seguinte notação: Repetir (Adicionar (forma; escala; translação; inter-relação; percprof), n,traj).

Para a etapa de verificação do modelo generativo proposto, foi utilizada uma família de produtos que usa a geometria da superfície como elemento unificador do conjunto. A Figura 8 ( $A, B$ e C) exemplifica visualmente a sequência de construção das geratrizes de três diferentes membros desta uma família, através de seus arcos de circunferência que constituem a superfície morfológica dos elementos. 
Figura 8 - Composição de Geratrizes através de Arcos Tangentes.
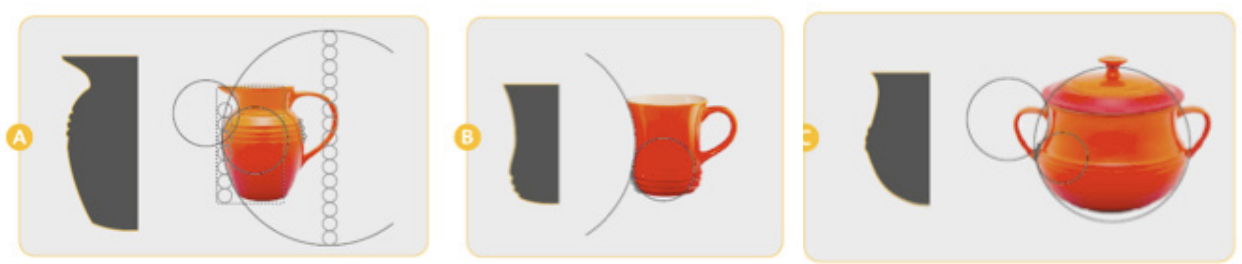

Fonte: o autor.

A seguir, o Quadro 5 apresenta as relações Gene-Função-Parâmetro para cada uma das geratrizes da Figura 8, que vêm a definir os seus cromossomos. Inicialmente estabelece-se a criação de área que organiza a altura do objeto, através da função 'CriarArea' inicializando-se os seus parâmetros. Em seguida são identificados o número de objetos de vocabulário utilizados para cada geratriz e parametrizados através da função 'Adicionar'. A função 'Repetir' organiza a reincidência de movimentos e operações e a função 'Subtrair' orienta a direção da geratriz em relação ao eixo. As codificações (sequenciamento de genes) se repetem até a finalização da composição geométrica euclidiana da forma. O conteúdo da variável Parâmetro, estabelece o grau de pertinência do gene em relação ao cromossomo, ou seja, a relevância da operação geométrica em relação à forma. No uso de algoritmos genéticos, este parâmetro pode ser aplicado para determinar a herança do gene, criando condições de manipular a prevalência (0 à 100\%) de uma determinada operação geométrica em sucessivas gerações de maneira análoga ao fenômeno da dominância (D) e recessividade $(R)$ no contexto biológico. O Quadro 5 apresenta também a simulação do formato gerado pela geratriz após o movimento de revolução.

\section{CONSIDERAC̣ÕES FINAIS}

Neste trabalho, foi apresentado um modelo generativo baseado em analogia biológica capaz de manter a coerência formal entre os membros de uma família de produtos, através da elaboração de um mecanismo baseado no princípio natural da hereditariedade que permite a derivação da morfologia de uma forma seminal para os demais membros do conjunto, mantendo-se assim coerência estilística da família.

O modelo generativo utilizou a gramática da forma como estratégia de composição e decomposição das geratrizes que descrevem a morfologia das superfícies de revolução, criando condições de manipular os seus elementos e seus operadores de maneira isolada, além de permitir a relação das equivalências entre os padrões geométricos, genéticos e computacionais. Em consequência, torna-se possível a troca de material genético entre duas distintas composições formais, ou seja, é possível derivar a geometria de um elemento A para um elemento $B$ de maneira integral ou parcial, simulando as operações da genética como combinação e mutação através de algoritmos genéticos (AGs). 
Quadro 5 - Composição Cromossômica das Geratrizes.

\begin{tabular}{|c|c|c|}
\hline \multicolumn{3}{|c|}{ Cromossomo Geratriz 1} \\
\hline Gene & Função & Parâmetro \\
\hline Gene 1 & CriarArea $(8,5,8)$ & \\
\hline Gene 2 & Adicionar(circulo; 15; 45"; "uniao"; 20\%) & R \\
\hline Gene 3 & Adicionar(circulo; 4,$5 ;-95^{\circ}$; "uniao"; $\left.100 \%\right)$ & D $50 \%$ \\
\hline \multirow{2}{*}{ Gene 4} & Repetir(Adicionar (circulo; 0,3; -90\%"; 'uniao'; 80\%); & D $100 \%$ \\
\hline & Subtrair(circulo; 0,3; 90\%; "unia0", 40\%); 3; Gene3) & \\
\hline Gene 5 & Subtrair(circulo; 4,$5 ;-30^{\circ} ;$ 'unia0', 096) & R \\
\hline Gene 6 & Finalizar 0 & \\
\hline \multicolumn{3}{|c|}{ Cromossomo Geratriz 4} \\
\hline Gene & Função & Parâmetro \\
\hline Gene 1 & CriarArea(h,s,n) & \\
\hline Gene 2 & Adicionar(circulo; 4,5; -950; "unia0"; 10066) & R \\
\hline \multirow[t]{2}{*}{ Gene 3} & Repetir(Adicionar (circulo; 0,3; -90'; 'unva0'; 8096); & D $100 \%$ \\
\hline & Subtrair(circulo; 0,3; 90\%; 'uniao', 40\%); 3; Gene2) & \\
\hline Gene 4 & Subtrair(circulo; 4,$5 ;-30^{\circ} ;$; uniao', ON) & $R$ \\
\hline Gene 5 & Finalizar0 & \\
\hline \multicolumn{3}{|c|}{ Cromossomo Geratriz 3} \\
\hline Gene & Função & Parâmetro \\
\hline Gene 1 & CriarArea(h,s,n) & \\
\hline Gene 2 & Adicionar(circulo; $15 ; 45^{\circ}$; "uniao"; 2015) & $050 \%$ \\
\hline Gene 3 & Adicionar(circulo; 4,$5 ;-95^{\circ}$; "uniao"; 100\%) & R \\
\hline \multirow[t]{2}{*}{ Gene 4} & Repetir(Adicionar (circulo; 0,3; -90'; 'uniao'; 8096); & D $100 \%$ \\
\hline & Subtrair(circulo; 0,3; 90\%; "uniao", 40\%); 3; Gene3) & \\
\hline Gene 5 & Subtrair(circulo; 4,$5 ;-30^{\circ} ;$; uniao", 096) & $R$ \\
\hline Gene 6 & Finalizar0 & \\
\hline
\end{tabular}

Fonte: 0 autor.

Além da contribuição do modelo generativo, evidenciado nas transcrições propostas: genética e computacional, esta pesquisa estabelece uma base de conhecimento para o uso dos algoritmos genéticos ( $A G$ 's) no processo de design apresentado um método sistemático para a sua implementação, o que pode significar um aumento expressivo de soluções projetuais uma vez que permite a geração e verificação de um maior número de combinações. 


\section{REFERÊNCIAS}

BACK, Nelson.; OGLIARI, André.; DIAS, Acires; SILVA, Jonny Carlos da. Projeto integrado de produtos. Barueri, SP: Manole, 2008.

BURNS, George W. Genética: uma introdução à hereditariedade. Rio de Janeiro: Guanabarra, 1986.

CELANI, Gabriela; CYPRIANO, Débora; GODOI, Giovana de; VAZ, Carlos Eduardo V. A Gramática da forma como metodologia de análise e síntese em arquitetura. Revista Conexão: Comunicação e Cultura (UCS), v. 5, n. 10, 2006.

CHA, Myung Yeol; GERO, John S. Shape pattern representation for design computation. Working Paper, Key Centre of Design Computing and Cognition, University of Sydney, Sydney. 2006.

DAVIS, Lawrence. Handbook of genetic algorithms. VNR Company Library, 1990.

GONÇALVES, Rodrigo T. Chomsky e o aspecto criativo da linguagem. Revista Virtual de Estudos da Linguagem - ReVEL, v. 5, n. 8, mar. 2007.

GRIFFITHS, Anthony J. F.; WESSLER, Susan R.; CARROLL, Sean B.; DOEBLEY, John. Introdução à genética. Rio de Janeiro, Guanabara, 2001.

LOBACH, Bernd. Design industrial: bases para a configuração dos produtos industriais. São Paulo: Edgard Blucher, 2001.

MITCHELL, William J. The logic of architecture. Cambridge, MA: MIT Press, 1992.

NACHTIGALL, Werner. Bionik als Wissenschaft: Erkennen - Absrahieren Umsetzen. Berlin: Springer, 2010. 
STINY, George. Introduction to shape and shape grammars: environment and planning B. London, 1980. v. 3, p. 343-351.

TEIXEIRA, Fábio Gonçalves. Um modelo evolutivo para o processo de geração e seleção de alternativas em design. In: CONGRESSO BRASILEIRO DE PESQUISA E DESENVOLVIMENTO EM DESIGN, 12., 2016, Belo Horizonte, 2016. Proceedings... Belo Horizonte, v. 9, n. 2, p. 4374-4384. 